\title{
Correction to: Taurine protects noradrenergic locus coeruleus neurons in a mouse Parkinson's disease model by inhibiting microglial M1 polarization
}

\author{
Liyan Hou ${ }^{1}$. Yuning Che ${ }^{1}$. Fuqiang Sun ${ }^{1}$. Qingshan Wang ${ }^{1}$
}

Published online: 13 February 2021

(c) Springer-Verlag GmbH Austria, part of Springer Nature 2021

Correction to: Amino Acids (2018) 50:547-556

https://doi.org/10.1007/s00726-018-2547-1

In the original publication of the article, Fig. 5 has been published with an error. The wrong blot of GAPDH was provided in Fig. 5D.

The authors apologize for this error and state that this does not change the scientific conclusions of the article.

The GAPDH blot has been replaced and the correct Fig. 5 is given in this correction.

The original article can be found online at https://doi.org/10.1007/ s00726-018-2547-1.

1 School of Public Health, Dalian Medical University, No. 9

W. Lvshun South Road, Dalian 116044, China 

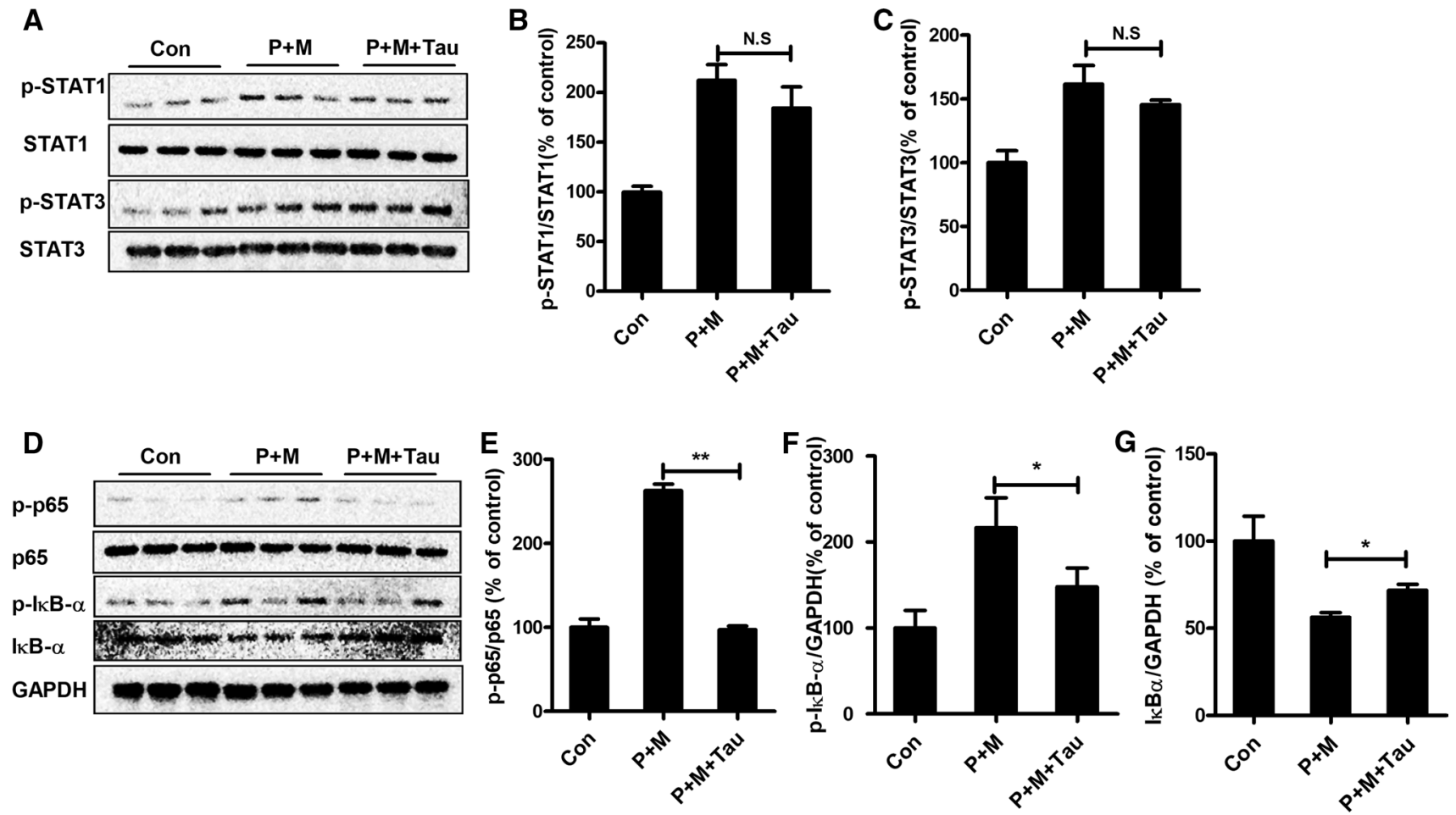

Fig. 5 Taurine blocks $\mathrm{P}+\mathrm{M}$-induced activation of NF- $\kappa \mathrm{B}$ but not STAT1/3 in brainstem of mice. a The levels of phosphorylated and nonphosphorylated STAT1 and STAT3 in brainstem of P+M-treated mice with or without taurine were determined by Western blot using specific antibodies and the representative blots are shown. $b$ The band density of STAT1 blots was quantified. c The band density of STAT3 blots was quantified. $\mathrm{d}$ The levels of phosphorylated and nonphos- phorylated p65 and I $\kappa \mathrm{B} \alpha$ in brainstem of $\mathrm{P}+\mathrm{M}$-treated mice with or without taurine were determined by Western blot using specific antibodies and the representative blots are shown. e The band density of p65 blots was quantified. $f$ The band density of phosphorylated-ІкB $\alpha$ blots was quantified. $g$ The band density of total IкB $\alpha$ blots was quantified. $* \mathrm{p}<0.05 . * * \mathrm{p}<0.01$; N.S not significant

Publisher's Note Springer Nature remains neutral with regard to jurisdictional claims in published maps and institutional affiliations. 